\title{
The Influence of Local Culture Inheritance on Country Brand Visual Image Design
}

\author{
Xiaojuan Huang \\ College of art and design, Hangzhou Polytechnic, Hangzhou, 311402, China
}

Keywords: Local culture inheritance, Country brand, Visual image.

\begin{abstract}
Rural tourism is a kind of tourism based on the local culture which has a typical country brand visual image. It plays a role on promoting the local rural tourism development. This indicates that the brand visual image which can represent the local attributes and cultural characteristics must be designed. This article takes Hangzhou region as an example to analyze the relationship between local culture inheritance and country brand visual image design from aspects such as the concept of rural local culture and reasons of country brand visual image localization design.
\end{abstract}

\section{Introduction}

In recent years, the constructions of new countryside are increasing. As an organic part of new countryside planning and construction, rural tourism plays an important role in the inheritance and protection of local rural culture. Rural tourism belongs to a kind of regional characteristic tourism which can reflect the characteristics such as local customs, architectural styles and farming culture etc. It has gradually become an important way for new rural farmers to increase their income. If one wants to promote the development of rural tourism industry, it is very important to have a country brand visual image which can represent the local culture. Therefore, in the design of country brand visual image, what effects does local culture inheritance have? How to realize the localization of country brand visual image design?

\section{The summary of country local culture}

A kind of regional culture which has strong countryside local presence, bearing certain history knowledge and digested with the modern culture, being able to show the rural human and natural features out is known as the rural local culture. ${ }^{[1]}$ For example, comedy, oral literature, craftsmanship, Chinese folk art forms, medicine, art and so on, all these cultural forms which reflect the countryside's hereditary spirit, custom, system and art belong to the rural local culture. ${ }^{[2]}$

\section{The significance of local culture inheritance on country brand visual image design}

Put the local culture in country brand visual image design is a choice of keeping up with the requirements of the development of the times, specifically including the following three aspects.

a). Conductive to Hangzhou's sticking to taking the road of rural tourism development. On design of rural tourism brand visual image, a series of functions are often required. The functions include the use function, cognitive function, function of art education and guidance function etc. The localization tourism visual image of all countryside in Hangzhou can be created and the awareness of country brand image can be improved through the combination of a variety of functions. It has a great significance on promoting the development of rural tourism industry in Hangzhou.

b). Conductive to the better inheritance of Hangzhou's rural local cultural connotations. Adhering to the goal of "creating country brand", integrating Hangzhou's characteristic local cultural background and characteristic country brand image and digging out the regional context such as rural folk-customs and folkways, architectural culture, art, culture, farming culture of the tourist area can better inherit Hangzhou's local rural culture.

c). Conductive to further promotion of the local culture's innovative design by the use of visual elements. With the influence of new ideas and new technologies, more rural areas tend to design and 
create some rural environment facilities with new ideas. Combined with methods such as thinking innovation, performance innovation and elements innovation, they rediscover, redesign and reorganize the local culture visual elements based on the local culture essence in the design of their brand visual image. This has effectively reflected the uniqueness and diversity of local culture visual design elements as well as delivered the positioning and properties of local brand.

\section{Factors should be considered in putting local culture into country brand visual image design}

\section{Brand value.}

It will make the the spiritual connotation of rural culture more abundant through the reconstruction of country brand value and further effectively promote the development of the local culture as well as people's identity on rural local culture, which is advantageous to enhance the influence of country brand. Country brand is the basic manifestation form of rural local culture. High quality of local cultural features can be showed in all directions through comprehensive development of rural culture so as to be in favor of setting up the confidence of innovation of rural local culture, and further promoting the rural tourism brand value.

\section{Visual identification system.}

The performance of visual recognition system is not only for shaping the brand image, but also having certain osmosis on inheritance and innovation of brand culture. Brand visual image design extracts essence from brand culture and conveys it to the audience, strengthening and deepening the cultural memory to make its cultural value really resonate with consumers. As for country brand, people's understanding of its concept is not deep. While the deepest feeling and memory it gives people are the completion of the design of concrete visual elements, precisely the design of brand VIS on the basis of relying on rural local culture connotations. ${ }^{[3]}$ Design types including apparel design, model design and advertising design, or image design of transport tools etc., all belong to brand VIS. ${ }^{[4]}$ The use of these designs can make one real understand the connotations of rural tourism brand visual image, identity and have a thorough understanding of various performances of visual identification, give more attention to the system design of country brand VIS.

\section{Local brand culture.}

As for country, local brand culture is considered to be the competitive power which has the most important values. Elements of country brand culture include a variety of associated elements such as rural nature, rural story, rural humanity etc. If the digest of villages, tourists and local culture was to be achieved, one should start conquering from the brand. The most important thing of conquering the brand is to conquer in the field of culture. Only in this way, a unique rural tourism brand image can be made. So, reconstruction of rural local brand culture is a core element must be considered for improving rural brand core competitiveness.

\section{The influence of local culture inheritance on country brand visual image design}

\section{Promote the inter-amalgamation and update of design concept.}

a). Promoting the integration of diversification and compound. Hangzhou's rural local cultural environment and geographical environment are characterized by diversity, this makes Hangzhou's culture present a characteristics of diversification. There are many elements of multielemental regional cultures, including tea culture, history culture, food culture, history culture, rural local celebrities relics etc. ${ }^{[5]}$ Through these cultural elements, one not can only learn about the regional culture with local diversity, but can also feel the rural local characteristic culture of Hangzhou. In this way, Hangzhou rural aboriginality has been set up. Rural local features have achieved free development and formed a grand situation of diversification, re-check change inter-amalgamated. This has positive significance on promoting the rural tourism in Hangzhou to take the road of internationalism and openness.

b). Promoting the integration of localization, globalization. Nowadays, the global regional culture become blurred on the boundaries. This makes the rural local culture more superior, providing strong support for the rural tourism brand image with local cultural characteristics established in the rural 
tourism market in the world. So, in the creation of country local brand visual image, the designer must take the rural local culture as the foundation and stick to the design philosophy of integration of nationality and cosmopolitan, modernity and tradition. Only in this way can the designer create the local brand visual image which is unique, able to inherit local culture and has prospects.

c). Promoting the integration of visualization and spiritualization. Conducting in-depth understanding on Hangzhou's rural culture and historical change can dig out the characteristic elements such as ancient spring, ancient trade road, ancient bridge, ancient folk house and ancient kiln which reflect local culture. After a full understanding of rural local cultural spirit connotations, it effectively implements the perfect combination of rural local visual elements and country brand spirit through digging out the relationship between local visual elements and country brand image design. This makes country brand become a visual symbol with deep cultural connotations.

\section{Renewing the design strategy of brand VIS.}

The country brand VIS is composed of various systems including elements such as humanistic system, rural natural system and the tourism basic system etc. ${ }^{[6]}$ Only through the organic combination of these elements, can a kind of deep cultural visual experience sets new, strange and beautiful as one be created, visitors have resonance with the rural tourism brand image from the spiritual. So, before the design, the designer should have a thorough understanding of Hangzhou's rural local culture through mining in-depth, sense and grasp Hangzhou's rural culture as visitor, besides combine it with spiritual connotations such as west lake natural culture of Hangzhou, Southern song dynasty traditional culture etc. and conduct deep excavation on rural local cultural elements through the understanding of culture such as local architecture, religion, folk customs passed from generation to generation, and then convert all these into visualized design elements. Then, determining what content of the local rural tourism brand visual image design should be needed. Content includes design target analysis and positioning, design idea's thinking and putting forward, finalizing design scheme and editing the design handbook in books etc.

1) Realization of the research analysis on rural local visual elements

a). The research analysis on the elements of folklore culture. The generation of folk-custom and folkway is a natural selection formed on the basis of people's conclusion of region characteristics and living after a long time. The folk-custom and folkway such as Nian Guan, diet custom etc. reflect the profound connotation of Chinese rural culture. People can feel the important value, local culture perspective height of folk culture tourism through these customs. It is not hard to find, folk customs in all the rural areas of Hangzhou have the characteristics such as diversity, rich folk customs etc. For example the Jiuxing Fisherman Shui Shang wedding, Silkworm festival, canal dragon boat race etc.

b). The research analysis on the local-style dwelling houses building cultural elements. There are diversity forms of culture which presents the rural human resources, while rural local-style dwelling houses is the most directly one with bright historical cultural, regional characteristics. Through the in-depth investigations on space layout, architectural form, hall configuration and the social function of rural traditional dwelling houses, the local visual elements can be extracted and be redesigned. For example, in the dwelling houses of big courts and ancient drama stages in Hangzhou, our country's ancient profound ethical and ritual thoughts can be read out. Through the analysis of these rural dwelling houses, designers can analyze their potential values of art in the composed graphics of buildings, wood carving and illuminating decorative patterns, refined traditional graphic patterns etc.

2) The realization of the reapplication of rural local visual elements

The application of graphic visual elements in rural brand visual elements

In a variety of ways reflect tourism brand personality, the localized differences of graphic elements is one of the most effective one. If a designer can extract out the rural local symbol and take some simple images as the symbolic signs to pass the local culture, and change these cultural elements into graphic elements with the help of methods such as moral, analogy and abstraction, and apply the graphic elements into the design of country brand image. This has made the appeal of local brand image promoted to a great extent.

The application of color vision elements in country brand visual image 
The design of country brand visual image generally includes a variety of visual languages while color is a relatively important one. The application of color in elements such as different natural landscape, history and culture, building style can present different color gamut, making the color system complex and diversified, creating profound local rural sense. [8] While the meaning of the application of color more runs over the infrastructure of the rural local culture, being evolved into sense of coloring of rural brand visual image system.

The application of text visual elements in country brand visual image

In the design of country brand visual image, the range of the content the text covers is relatively broad, while the font design is considered as the most important element. ${ }^{[9]}$ Hangzhou countryside' s local words inherits the pictographic font of China. Sticking to the integration with local culture in country brand visual image design on the one hand embodies the design principle of the combination of image and functions, on the other hand highlights the distinctive brand visual image and regional local properties, while the pictographic font meets these two conditions. For example, in the design of visual image of brands and logos of ancient villages or towns in Hangzhou, it is easy to feel the rich history and culture breath in writing with writing brush which highlights the rural local cultural characteristics.

3) The realization of continuity of process of country brand visual image design

The emphasis point of country brand VIS mainly includes two aspects: (1) The design of the basic system, for example, the country logo image planning, mascot design, slogan design etc; (2) The design of the application system including guidance system design and application of public service, souvenirs design etc. ${ }^{[10]}$ Relying on the two above, the construction of country brand localization design system with continuity can be quickened through increasing design systems such as rural environment decoration system, natural landscape development promotion system etc.

\section{Conclusion}

Hangzhou is a famous tourist resort wherein no lack of beautiful rural tourism resorts and brand countrysides with the characteristics of local culture. In the design of country brand visual image, only by full introduction of design concept of internationalization and modernization, rooted in the native culture, and the enhancement of the update of technology, talent, management and market can rural local culture content of Hangzhou be further improved while the innovative country brand visual image with local cultural characteristics could be worked out, and thus the tourist experience quality be improved.

\section{References}

[1] Chen Wang, Chen Shang Wu. The brand visual design research under Chinese traditional art graphics context, Journal of brand, 2015 (11) : 254-255.

[2] Zhao Jun Xiang. Cultural inheritance in China's urbanization process, Journal of Shandong University (philosophy and social sciences edition), 2014 (04) : 34-43.

[3] Mao Yan Juan, Yang Chao Hui, Fang Min. Local elements thinking in Suzhou silk brand visual image design, Design, 2016(03):42-43.

[4] Li Long, Song Hui. Image creation and dissemination mechanism research on rural tourism destinations in north of Anhui Province, Journal of market modernization, 2015 (27) : 143-145.

[5] Shen Zhou Feng. The relation between brand culture and visual image design , Journal of new art, 2013 (9) : 123-124.

[6] ZangRui, Yan Tiantian. The application of traditional auspicious symbols in brand visual image design , Science and technology, 2015 (12) : 181. 
[7] Li Yong Jun. Thick with leaves and deep-rooted·full of life--Research on Guangdong cultural visual image brand integration construction and improvement of design practice , Journal of arts education, 2014 (6) : 132-133.

[8] Duan You Wen, Wang Heyi. Discussion on the deep integration of ancient village traditional culture resources and creative industries--taking Yan Jing village of Wan Rong county in Shanxi Province as an example , Journal of Shanxi University (philosophy and social sciences edition), $2014((01): 131-140$.

[9] Ming Lan, Li Hui. Study on Hunan old brand visual image redesign, Journal of packaging world, $2015(02): 4$ to 6.

[10] Zhao Qin, Huang Qi. The application of "six color" regional culture element in Jiangxi City brand visual image creation, Packing engineering, 2015,36(20):21-25. 